\title{
KREBER`S ADVENTURES: COMPUTER GAME ABOUT THE ATP FORMATION
}

\author{
Baêta, F.J. ${ }^{1}$, Souza, B.M. ${ }^{1}$, Marinho, G.B. ${ }^{1}$, Andrade, J.G. ${ }^{1}$, Souza, J.C. ${ }^{1}$, Bertoldi, \\ M.L.M. ${ }^{1}$, Hornink, G.G. ${ }^{2}$ \\ ${ }^{1}$ Biomedicine undergraduate course, Federal University of Alfenas, Minas Gerais, \\ Brazil; ${ }^{2}$ Biochemistry Departament, Biomedical Institute, Federal University of Alfenas, \\ Minas Gerais, Brazil
}

Introduction: Biochemistry, as well as other subjects related to molecular area, have several abstract and difficult concepts to be understood, therefore, many educational innovations have been developed, highlighting the digital games. The digital games feature a playful and motivational character that encourages students during the concepts learning, with a different way to learning the concepts studied. Objectives: The objective of this study was the development of a computer game focused on the concepts of ATP formation, including the glycolytic pathway, Krebs cycle and Electron Transport Chain, as well as aspects related to the regulation, and evaluate the usability of it, as well as some evidence of its educational potential. Material and methods: The development of the game followed the following steps: definition of the subject; understanding of game developer (it was chosen the GameMaker); storyboard creation of the game; prototyping, implementation and usability testing. For the evaluation, inspection usability was performed (without involving end users) and subsequently the cognitive route and the usability questionnaire (the latter two with students of the discipline of Biochemistry). Results: The game approached the energy metabolism in three phases: the glycolytic pathway, Krebs cycle and electron transport chain. Each phase has a different purpose, with some questions about the ways. To complete the game, you must correctly answer the questions, avoid the obstacles and achieve the goals of each phase. After usability testing, it found that users could, in a playful manner, actively interact with the content addressed and, through the difficulties presented in the game, had the opportunity to expand and review their knowledge. Conclusions: The game was identified as a motivating and innovative proposal for teaching, and it had good usability for undergraduate students. The ludic worked as a pedagogical practice encourages student for learning and may assist in the construction of knowledge.

Keywords: ATP, digital game, arcade

Acknowledgements: FAPEMIG 